[CONTRIBUTIONS FROM THE LABORATORY OF THF PENNSILVANIA STATE COLIEGE AGRICUITURAI EXPERIMENT STATION.]

\title{
$X$. CREAMING OF MILK DURING ITS SALE.
}

BY WILLIAM FREAR AND M. H. IINGREE.

Received July 25 , jogr.

THE theory that the creaming tendency of milk leads to a pronounced separation of this liquid into a fat-rich upper layer and fat-poor lower stratum under the conditions prevailing during the delivery of milk on a wagon-route or during its retailing in the shop, has sometimes been set up as a defense in prosecutions for adulteration of milk by skimming.

The experiments of Wing and Smith ${ }^{1}$ satisfactorily show that milk delivered to customers on a wagon-route from a large can by means of a dipper that rests, when not in use, on the bottom of the can, is practically homogeneous. Dean ${ }^{2}$ has shown that this is also true of milk that is distributed on a wagon-route, the liquid being delivered from large cans through a faucet.

The range of conditions that may occur during the retailing of mill: from a shop, has not been so satisfactorily covered.

Carter Bell ${ }^{3}$ examined a sample taken from two gallons of wellmixed milk to establish its initial composition. The milk was then set in a cool place and one pint withdrawn hourly, pains being talien! to stir the milk as little as possible during the withdrawal; the total solids and fat in the iractions thus taken varied irregularly to the extent of 0.64 per cent.; there was no important separation of cream at any time; in fact, the last pint was richest in fat.

The writer has recently had occasion to consider the possibilities of separation under the following conditions: The sale of a small guantity of milk, kept in a jar set in a trough of cold water, delivered to customers in portions of a pint to a quart at irregular intervals curing a period of six to eight hours, the milk being taken from the jar (without care to stir the contents) by means of a dipper, which is not returned to the jar but laid to one side during the intervals between sales to permit the close covering of the ressel.

In the experiment made to determine the effect of such con-

1 Cornell Agricultural Experiment Station, Bulletin No. 20.

- Ontario Agricultural College, Bulletin No. 66 .

"A Aalys, No. 2I, December, I87-: cited by Blyth: "Foods," 4th ed., p. 334. 
ditions upon the final composition of the milk, a rather deep can was substituted for the jar, otherwise the conditions were exactly as stated above. Two gallons of milk were used, having first been thoroughly mixed and sampled at 8.30 A.M.; at times stated, below, quantities of approximately one pint were withdrawn by a scooping motion of the dipper. The fractions thus withdrawn were analyzed by the usual creamery methods, $i$. e., the fat was determined by the Babcock test, in duplicate; the duplicates gave identical results in all but two instances, where differences of 0.10 per cent. occurred. The density was determined by use of a Quevenne lactometer, with due correction for temperature variations; the readings were made to one-fifth degree, though the tendency of milk to coat the stem and obscure the scale of the lactometer makes it doubtful whether an accuracy of more than one-half to one-third degree is possible. The total solids were computed from the data thus obtained, by use of the Babcock short formula :

$$
\text { Total solids }=\frac{L}{4}+1.2 f,
$$

where $L$ represents the Quevenne lactometer reading corrected to $60^{\circ} \mathrm{F}$., and $f$ represents the percentage of fat in the milk. Owing to the limitations of the lactometric method mentioned above, it is doubtful whether the solids determinations can be made more closely than 0.08 to 0.12 per cent.

The entire detail of the experiment was carried out by M. $\mathrm{H}$. Pingree.

The results obtained were as follows:

\begin{tabular}{|c|c|c|c|c|}
\hline Time. & $\begin{array}{c}\text { Fat. } \\
\text { Per cent. }\end{array}$ & $\begin{array}{l}\text { Quevenne lac- } \\
\text { tometer readings. } \\
\left(60^{\circ} \mathrm{F}\right) .\end{array}$ & $\begin{array}{l}\text { Total } \\
\text { solids. } \\
\text { Per cettit. }\end{array}$ & $\begin{array}{l}\text { Solids, } \\
\text { not fat. } \\
\text { Per cent. }\end{array}$ \\
\hline 8.30 A.M........ & 4.35 & 34.0 & 13.72 & 9.37 \\
\hline In $A . M \ldots \ldots \ldots$ & 7.45 & 3I.I & 16.69 & 9.24 \\
\hline II A.M.......... & 7.20 & 32.0 & I 6.64 & $9 \cdot 44$ \\
\hline I $2 \mathrm{M} \ldots \ldots \ldots \ldots$ & 6. 10 & 32.8 & 15.52 & $9 \cdot 42$ \\
\hline 2 P.M........... & 5.90 & 32.8 & 15.28 & $9.3^{8}$ \\
\hline 2.30 Р.M........ & 4.80 & 33.4 & I 4. I I & $9.3 \mathrm{I}$ \\
\hline P.M........... & 4.10 & $34 \cdot 3$ & I 3.49 & 9.39 \\
\hline
\end{tabular}

It is probable that the lactometer reading at Io A.M. was slightly too low; otherwise the analytical results check within the allowable limits of error. 
The results show very clearly that customers buying the second to sixth portions of milk inclusive. would receive much more than their share of the fat, and the last comers a greatly impoverished milk, when the conditions of sale resemble those of this experiment.

\section{NEW BOOKS.}

On Cane-Sugar and the Process of Its Mantfacture in Java. By H. C. PRinsen GeER1,Igs. Publisherl in the office of the Sugar-Cane, Altrincham.

This book contains brief statements of the chemical compositions of the sugar-cane. In addition to the cane-sugar, which is the principal constituent from a technical standpoint, the sugarcane consists of water ancl cellulose or fiber. The fiber is about 70 per cent. pure cellulose and 30 per cent. wood-gum or xylan. The organic acids are glycolic, malic, succinic and small quantities of tannic. Citric, tartaric and aconitic acids are said by some investigators to exist in normal sugar-cane, but these statements lack confirmation. The lime salts of these organic acids are soluble and are therefore not removed by clarification. From a technical point of view the organic acids which are formed by the action of lime during evaporation of the juices are of quite as much importance as those which exist naturally in the cane. These latter acids are lactic, saccharinic, gluconic, and saccharic. Acetic acicl only exists in cane which has unclergone fermentation.

The nitrogenous bodies of the cane are chiefly albumen, amides, or amino acicls and xanthine bases. It is not certain whether the anicles or amino acicis consist of asparagine, aspartic acid or glycocol. Xanthine bases are composecl chiefly of guanine. The total nitrogen in a mature sugar-cane does not exceed one-tenth of I per cent.

The coloring-matters of the cane are chiefly chlorophyll and its alteration products and anthocyan. There is also another coloring-matter in the fiber which becomes yellow on contact with alkaline licuids. The cane wax which exists on the outside of the cane is soluble in alcohol, ether, chloroform and benzine. It is not a wax properly so-called, but a saturated alcohol, having 24 atoms of carbon. In addition to the sucrose, levulose, and dextrose which form the chief part of the soluble carbohydrates, the 